\title{
Influence of topical human epidermal growth factor on postkeratoplasty re-epithelialisation
}

M M M J Dellaert, T A Casey, S Wiffen, J Gordon, P Johnson, A J M Geerards, W J Rijneveld, L Remeijer, P G H Mulder, W H Beekhuis

\begin{abstract}
Aim-To test the efficacy and safety of recombinant human epidermal growth factor (hEGF) on corneal reepithelialisation following penetrating keratoplasty.

Methods-A prospective, randomised, placebo controlled study was carried out in which patients were matched for diagnosis and received either hEGF ophthalmic solution $(30 \mu \mathrm{g} / \mathrm{ml}$ or $100 \mu \mathrm{g} / \mathrm{ml})$ or placebo in a double masked fashion. Matched pairs of patients received donor corneas from the same donor and were operated by the same surgeon on the same day. At the end of surgery all donor epithelium was removed mechanically. Patients were examined twice daily and fluorescein stained photographs were taken until the epithelium had closed. The area of the defect was measured by planimetry of the fluorescein stained defect on the photographs.

Results-There were no significant differences in re-epithelialisation of the donor cornea between the placebo group and the group treated with $30 \mu \mathrm{g} / \mathrm{ml}$ hEGF. Time until complete closure was slightly longer with $100 \mu \mathrm{g} / \mathrm{ml}$ hEGF compared with 30 $\mu \mathrm{g} / \mathrm{ml} \mathrm{hEGF}$ and with placebo. Mean healing rate of the epithelial defect with 100 $\mu \mathrm{g} / \mathrm{ml}$ hEGF was significantly slower than in the other groups.

Conclusion-No significant acceleration of corneal re-epithelialisation was demonstrated with the use of recombinant hEGF after penetrating keratoplasty in humans. (Br f Ophthalmol 1997;81:391-395)
\end{abstract}

Department of Epidemiology and Biostatistics, Erasmus University, Rotterdam, the Netherlands

P G H Mulder

Correspondence to: W Houdijn Beekhuis, Cornea Service, Rotterdam Eye Hospital,

Schiedamsevest 180, 3011

BH Rotterdam, the

Netherlands.

Accepted for publication 28 January 1997

Rapid corneal re-epithelialisation after penetrating keratoplasty is crucial for graft survival. Epithelial defects increase the risk of infection, vascularisation, thinning, perforation, and rejection of the graft. Any substances which accelerate wound healing could reduce these risks. In vitro and in vivo studies have shown the important role of epidermal growth factor (EGF) in growth regulation. EGF is a naturally occurring monomeric polypeptide and specific EGF receptors have been found to be localised in the cell membranes of conjunctival epithelium, corneal epithelium and endothelium, posterior pigmented layer of the iris, and the lens epithelium. ${ }^{1}$ Binding of EGF to its transmembrane receptor activates an intercellular cascade resulting in several metabolic events, including stimulation of proliferation and differentiation of epidermal and other cells. ${ }^{1}$ Previous studies of the influence of topically applied EGF on corneal wound healing have been promising. In organ culture and animal in vivo studies, epidermal growth factor isolated from mouse submaxillary glands (mEGF) stimulated proliferation and DNA synthesis of corneal epithelium and increased the epithelial healing rate. ${ }^{2-6}$ Furthermore, tensile strength of corneal wounds in rabbits was increased by application of mEGF. ${ }^{7}$

Conflicting results of the effect of mEGF on corneal epithelium in humans have been reported. While in 1979 Daniele $e t a l^{8}$ reported an acceleration in the healing of nondystrophic diseases of human corneal epithelium by mEGF, Kandarakis et $a l^{9}$ could not demonstrate any benefit of $\mathrm{mEGF}$ on epithelial healing after penetrating keratoplasty. In the mid 1980s biosynthetic human EGF (hEGF), produced by yeast recombinant DNA techniques, became available. ${ }^{10}$ Acceleration of re-epithelialisation and a significant increase in stromal wound strength was demonstrated in in vivo studies on full thickness incisions in rabbit and primate corneas treated with recombinant hEGF. ${ }^{11-13}$

A prospective, randomised, double masked, placebo controlled study was conducted to evaluate the effect of recombinant hEGF on epithelial wound healing following penetrating keratoplasty in humans.

\section{Methods}

The research followed the tenets of the Declaapproved by the ethics committees of the individual hospitals. Patients scheduled for penetrating keratoplasty (with a diagnosis of keratoconus, pseudophakic bullous keratopathy, and Fuchs' dystrophy), who met all protocol entry criteria and were willing to participate, were enrolled in the study. Patients with a history of herpetic infections, glaucoma, or uveitis ration of Helsinki and the study protocol was 
Table 1 Indications for penetrating keratoplasty

\begin{tabular}{lllll}
\hline & $\begin{array}{l}h E G F \\
(100 \mu \mathrm{g} / \mathrm{ml})\end{array}$ & Placebo & $\begin{array}{l}h E G F \\
(30 \mu \mathrm{g} / \mathrm{ml})\end{array}$ & Placebo \\
\hline Keratoconus & 4 & 4 & 6 & 5 \\
Pseudophakic BKP & 1 & 1 & 1 & 1 \\
Fuchs' dystrophy & 4 & 4 & 2 & 3 \\
Total & 9 & 9 & 9 & 9 \\
\hline
\end{tabular}

$\mathrm{hEGF}=$ human epidermal growth factor; $\mathrm{BKP}=$ bullous keratopathy.

Table 2 Demographic variables of all 36 patients under study

\begin{tabular}{|c|c|c|c|c|}
\hline & $\begin{array}{l}h E G F \\
(100 \mu g / m l) \\
(n=9)\end{array}$ & $\begin{array}{l}\text { Placebo } \\
(n=9)\end{array}$ & $\begin{array}{l}h E G F \\
(30 \mu g / m l) \\
(n=9)\end{array}$ & $\begin{array}{l}\text { Placebo } \\
(n=9)\end{array}$ \\
\hline Mean age (SD) (years) & $55.96(19.94)$ & $52.14(19.32)$ & $44.59(22.97)$ & $42.36(26.20)$ \\
\hline $\operatorname{Sex}(M / F)$ & $4 / 5$ & $6 / 3$ & $3 / 6$ & $3 / 6$ \\
\hline \multicolumn{5}{|l|}{ Race } \\
\hline White & 7 & 9 & 9 & 6 \\
\hline Asian & 1 & 0 & 0 & 2 \\
\hline Hispanic & 1 & 0 & 0 & 0 \\
\hline Other & 0 & 0 & 0 & 1 \\
\hline
\end{tabular}

in the operative eye, no corneal sensation, a Schirmer's test less than $5 \mathrm{~mm}$ per 5 minutes, and patients requiring the use of a bandage lens or having a tarsorrhaphy immediately after penetrating keratoplasty were excluded from the study. Written informed consent was obtained after explanation of the study purpose, procedures, and patients' responsibilities to the potential participant. Patients were matched in pairs. One patient of each pair was randomly assigned to receive topical treatment with hEGF (either $30 \mu \mathrm{g} / \mathrm{ml}$ or $100 \mu \mathrm{g} / \mathrm{ml}$ ) and the other patient to receive placebo. Neither the investigator nor the patient was aware of the treatment group assignment until after completion of the study.

The study medication was provided by Chiron Vision in sealed packages assigned to matched pairs of patients. Human epidermal growth factor ophthalmic solution (hEGF), derived from yeast cultures using recombinant DNA technology, was used as a unit dose, unpreserved solution at a concentration of 30 $\mu \mathrm{g} / \mathrm{ml}$ or $100 \mu \mathrm{g} / \mathrm{ml}$ in phosphate buffered saline with stabilisers. Placebo consisted of the same vehicle solution excluding the hEGF, and was provided as a unit dose, unpreserved solution, identical in appearance to the hEGF solution. On day 0 of the study each patient had penetrating keratoplasty performed using standard microsurgical techniques. Each pair of matched patients was operated on the same day, by the same surgeon, and received mate

Table 3 Summary of surgical data of all 36 study patients underdoing penetrating keratoplasty

\begin{tabular}{lllll}
\hline & $\begin{array}{l}h E G F \\
(100 \mu g / m l) \\
(n=9)\end{array}$ & $\begin{array}{l}\text { Placebo } \\
(n=9)\end{array}$ & $\begin{array}{l}h E G F \\
(30 \mu g / m l) \\
(n=9)\end{array}$ & $\begin{array}{l}\text { Placebo } \\
(n=9)\end{array}$ \\
\hline $\begin{array}{l}\text { Donor size (mm) (mean } \\
\quad(\mathrm{SD}))\end{array}$ & $7.75(0.25)$ & $7.75(0.25)$ & $7.67(0.25)$ & $7.78(0.26)$ \\
$\begin{array}{l}\text { Bed size (mm) (mean } \\
(\mathrm{SD}))\end{array}$ & $7.44(0.17)$ & $7.44(0.17)$ & $7.93(0.22)$ & $7.50(0.25)$ \\
ECCE & 3 & 3 & 1 & 1 \\
IOL removed & 1 & 1 & 0 & 1 \\
IOL implant & 4 & 4 & 1 & 2 \\
$\quad$ PC & 3 & 3 & 1 & 1 \\
$\quad$ Iris & 1 & 1 & 0 & 1 \\
Vitrectomy & 1 & 1 & 2 & 0 \\
Complications & 1 & 0 & 0 & 1
\end{tabular}

ECCE = extracapsular cataract extraction; $\mathrm{IOL}=$ intraocular lens; $\mathrm{PC}=$ posterior chamber lens; Iris $=$ iris fixated lobster claw lens. donor corneas; these corneas were preserved in tissue culture medium (MEM). ${ }^{14}$ Identical suture technique, graft size, and recipient bed size were used for both corneas of the pair. For combined cataract surgery and intraocular lens implantation matching was also done. After the graft had been sutured, all donor epithelium was removed mechanically by microsponge wiping. Fluorescein was instilled to verify complete epithelial removal on the surface of the graft. At the end of the procedure antibiotics (gentamicin) and steroid (betamethasone) were injected subconjunctivally and two drops of the study medication were administered. The eye was then pressure patched until the next morning.

Postoperative medication consisted of study medication administered four times a day until the epithelial defect was closed; chloramphenicol $0.5 \%$ eyedrops three times a day; and prednisolone $0.5 \%$ eyedrops six times a day, all without preservatives. Prednisolone and chloramphenicol drops were administered 2 hours after instillation of the study medication.

Patients were examined twice daily from day 1 until complete epithelial closure. The anterior segment was inspected for signs of inflammation, signs of conjunctival ischaemia, size of the epithelial defect, and superficial punctate keratopathy. A colour photograph of the cornea was taken 5 seconds after instillation of fluorescein. A slit-lamp connected photocamera was used with a magnification of $75 \times$ $(12.5 \times-6 \times)$ and Kodak PRD 135-36 200 ASA colour films. Photographs were processed in an IMAGEnet system (Topcon, Itabashiku, Tokyo, Japan). From the converted photograph on the screen the area of the defect could be estimated by planimetry. Paired Student's $t$ test was used to compare mean time to complete closure of the defect between groups. To estimate the percentage decrease in the area of the defect, a random coefficients model (rmANOVA) with time was used, after expressing the area as percentage of baseline and taking the logarithm of this percentage. Follow up examinations were performed 1 week, 1 month, 6 months, 1 year and, if possible, 2 years postoperatively. Best corrected visual acuity was measured and slit-lamp examination of the anterior segment was performed at each examination. On days 7 and 28 central corneal thickness was estimated by ultrasonic pachymetry and intraocular pressure was measured.

\section{Results}

Thirty six patients entered the study, nine receiving $100 \mu \mathrm{g} / \mathrm{ml} \mathrm{hEGF}$, nine receiving 30 $\mu \mathrm{g} / \mathrm{ml} \mathrm{hEGF}$, and each paired with a patient receiving placebo. In all but one case, matched pairs had the same indication for penetrating keratoplasty (Table 1). There were no important demographic differences between the treated and the control groups (Table 2). Data relevant to the surgical procedure are shown in Table 3. Twenty five patients underwent penetrating keratoplasty only. Eight patients had penetrating keratoplasty combined with extracapsular cataract extraction and implantation of a posterior chamber lens in the capsular 


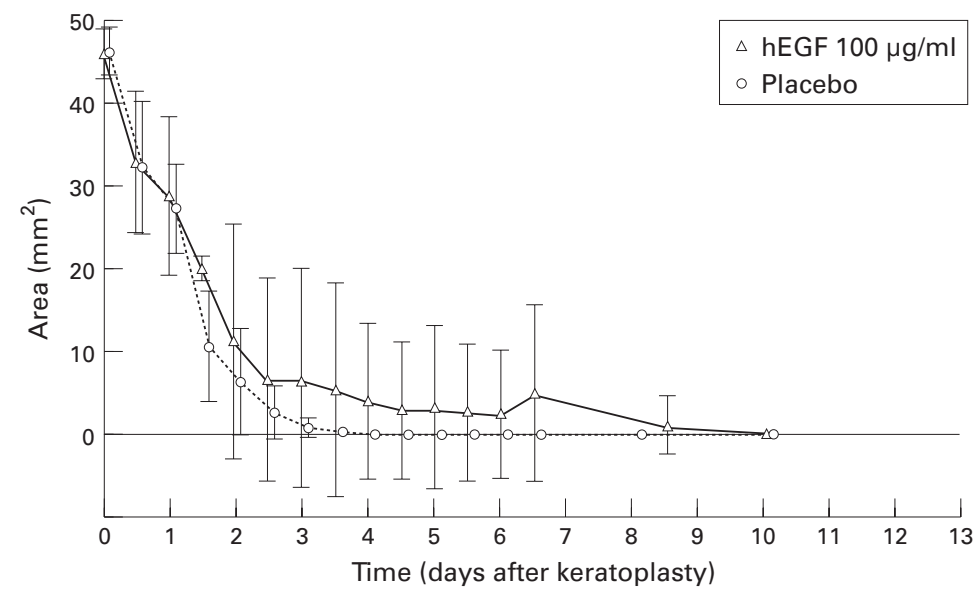

Figure 1 Change in area of epithelial defect with time after penetrating keratoplasty. Size of defect at day 0 was the size of the recipient bed. Each point represents the mean (SD); area of epithelial defect was estimated by planimetry.

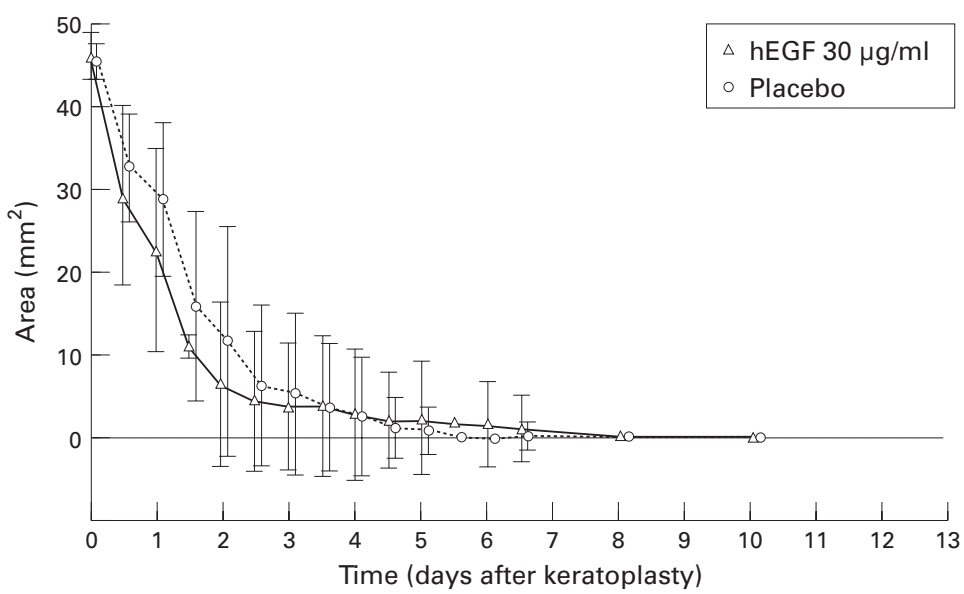

Figure 2 Change in area of epithelial defect with time after penetrating keratoplasty. Size of defect at day 0 was the size of the recipient bed. Each point represents the mean (SD); area of epithelial defect was estimated by planimetry.

bag. Three of the patients with pseudophakic bullous keratopathy underwent removal of the intraocular lens followed by implantation of an iris fixated intraocular lens (Worst Lobster Claw lens, Ophtec, Groningen, the Netherlands). In three of the latter cases anterior vitrectomy was performed. The one intraoperative complication was a rupture of the posterior lens capsule during extracapsular cataract extraction.

The primary efficacy variable was time to complete healing of the epithelial defect. Figures 1 and 2 show the mean size of the defect, estimated by planimetry at each examination until complete closure, for the group receiving $100 \mu \mathrm{g} / \mathrm{ml} \mathrm{hEGF}$ and the placebo group and the group receiving 30 $\mu \mathrm{g} / \mathrm{ml} \mathrm{hEGF}$ and the placebo group. Size of the baseline defect (size of defect at day 0) was the size of the recipient bed. There were no signifi-

Table 4 Corneal thickness ( $\mu \mathrm{m}$ ) on days 7 and 28 following penetrating keratoplasty (mean (SD))

\begin{tabular}{lllllll}
\hline & $\begin{array}{l}h E G F \\
(100 \mu g / m l)\end{array}$ & Placebo & $p$ Value & $\begin{array}{l}h E G F \\
(30 \mu g / m l)\end{array}$ & Placebo & p Value * \\
\hline Day 7 & $693(74)$ & $612(62)$ & 0.002 & $655(50)$ & $663(75)$ & 0.709 \\
Day 28 & $523(37)$ & $536(38)$ & 0.268 & $533(50)$ & $547(58)$ & 0.609 \\
\hline
\end{tabular}

^Paired Student's $t$ test. cant differences between treated and control patients in mean time until complete closure of the epithelial defect. Healing time was slightly longer in the $100 \mu \mathrm{g} / \mathrm{ml} \mathrm{hEGF}$ group compared with the placebo group, mean 5.1 (SD 4.3) days versus $3.4(1.0)$ days $(p=0.232)$, and also longer than in the $30 \mu \mathrm{g} / \mathrm{ml} \mathrm{hEGF}$ group and its control group, 3.9 (3.1) days versus 3.5 (1.7) days $(\mathrm{p}=0.718)$. Mean percentage decrease of the defect area per 12 hours was $29 \%$ in the $100 \mu \mathrm{g} / \mathrm{ml} \mathrm{hEGF}$ group compared with $44 \%$ in its placebo group ( $\mathrm{p}<0.0005)$. In the $30 \mu \mathrm{g} / \mathrm{ml} \mathrm{hEGF}$ group the percentage decrease was $52 \% / 12$ hours compared with $35 \% / 12$ hours in its placebo group $(\mathrm{p}=0.147)$.

Within the first postoperative week a transient fibrinous reaction was seen in seven eyes-three in the group of patients treated with $100 \mu \mathrm{g} / \mathrm{ml} \mathrm{hEGF}$, one in the group treated with $30 \mu \mathrm{g} / \mathrm{ml} \mathrm{hEGF}$, and three in the placebo control group. All affected eyes had other surgical procedures performed in addition to the penetrating keratoplasty. No correlation between the fibrinous reaction and the use of either the $100 \mu \mathrm{g} / \mathrm{ml}$ or the $30 \mu \mathrm{g} / \mathrm{ml} \mathrm{hEGF}$ could be demonstrated. In two eyes an inflammatory reaction around a few of the nylon sutures on the recipient side was noted; one eye was treated with placebo and the other with 30 $\mu \mathrm{g} / \mathrm{ml} \mathrm{hEGF}$. During the first postoperative days all eyes showed conjunctival hyperaemia. There was no conjunctival oedema or capillary closure which could have been associated with the subconjunctival injection of gentamicin at the end of surgery. ${ }^{15}$ Mean pachymetry measurements at days 7 and 28 following keratoplasty are shown in Table 4 . The nine patients receiving $100 \mu \mathrm{g} / \mathrm{ml} \mathrm{hEGF}$ therapy showed a significantly thicker cornea compared with the placebo control group at day 7 . There were no significant differences in intraocular pressure between the groups at any time.

Follow up results at 6 months, 1 year, and 2 years after surgery are shown in Table 5 . Complications were encountered in six cases. Three patients needed revision of their sutures-one in the placebo group, one in the group treated with $30 \mu \mathrm{g} / \mathrm{ml} \mathrm{hEGF}$, and one in the group treated with $100 \mu \mathrm{g} / \mathrm{ml}$ hEGF. Overall, more suture related problems (loose sutures, infiltrates at suture sites) were encountered in the total population of study patients than are generally seen in our routine keratoplasty cases. One patient receiving placebo treatment required a second penetrating keratoplasty in the operated eye because of nebulae formation in the graft, caused by a stromal allograft reaction. One other patient in the placebo group did have a transient endothelial rejection reaction which resolved with steroid therapy. A true rejection reaction requiring repeat penetrating keratoplasty was seen at 19 months postkeratoplasty in one patient treated with $100 \mu \mathrm{g} / \mathrm{ml} \mathrm{hEGF}$. All other eyes in both the hEGF treated groups and the placebo groups did comparably well. 
Table 5 Follow up results

\begin{tabular}{|c|c|c|c|c|c|c|c|c|c|c|c|c|}
\hline & \multicolumn{3}{|c|}{$h E G F(100 \mu g / m l)$} & \multicolumn{3}{|c|}{ Placebo } & \multicolumn{3}{|c|}{$h E G F(30 \mu g / m l)$} & \multicolumn{3}{|c|}{ Placebo } \\
\hline & No & $C$ & $V A$ & No & $C$ & $V A$ & No & $C$ & $V A$ & No & $C$ & $V A$ \\
\hline 6 Months & 9 & $\mathrm{a}$ & 0.4 & 9 & $\mathrm{~b}$ & 0.6 & 9 & a & 0.7 & 9 & $\mathrm{a}, \mathrm{c}$ & 0.7 \\
\hline 1 Year & 8 & 0 & 0.5 & 8 & 0 & 0.7 & 9 & $\mathrm{a}$ & 0.7 & 7 & $\mathrm{c}$ & 0.7 \\
\hline 2 Years & 7 & $\mathrm{~d}$ & 0.7 & 8 & 0 & 0.8 & 9 & 0 & 0.7 & 7 & 0 & 0.7 \\
\hline
\end{tabular}

No = number of patients. $C=$ complications: $a$, suture problem; $b$, endothelial rejection; c, stromal rejection $\rightarrow$ repeat penetrating keratoplasty; d, endothelial rejection $\rightarrow$ repeat penetrating keratoplasty; 0 , no complications. VA = best corrected mean visual acuity (Snellen fraction).

\section{Discussion}

Epidermal growth factor has been demonstrated by radioimmunoassay to be present in human tears. ${ }^{16}{ }^{17}$ Compared with the tear film of healthy control eyes, the concentration of EGF in the tear film of eyes with ocular surface disease is significantly lower. ${ }^{18}$ In such cases, including penetrating keratoplasty, an increase in EGF concentration to enhance epithelial recovery would seem desirable. In this study we tested the efficacy and safety of hEGF eyedrops on re-epithelialisation of the denuded human cornea after penetrating keratoplasty. The effect of two different dosages of hEGF, $30 \mu \mathrm{g} / \mathrm{ml}$ and $100 \mu \mathrm{g} / \mathrm{ml}$, were compared with the effect of placebo, in a double masked fashion. This is, to our knowledge, the first report on the use of recombinant hEGF in humans. There were no significant differences in re-epithelialisation of the donor cornea after penetrating keratoplasty between the group treated with $30 \mu \mathrm{g} / \mathrm{ml} \mathrm{hEGF}$ and placebo control group. Mean healing time to closure of the defect with topical application of $100 \mu \mathrm{g} / \mathrm{ml}$ hEGF was actually slightly longer compared with the other three groups. This is reflected in the significantly lower percentage decrease of the defect area per 12 hours after treatment with $100 \mu \mathrm{g} / \mathrm{ml}$ hEGF. This could be explained by down regulation of the receptor sites. ${ }^{19}$ Binding of hEGF to its plasma membrane receptor is followed by internalisation and degradation of the EGF-receptor complex, without concomitant production of new receptors. If an abundance or excess of EGF is presented to the receptors all receptor sites will be occupied and for some time no receptor sites will be available. ${ }^{11}$

A high incidence of suture related problems was noted in this study, both in the group treated with hEGF and in the placebo control group. This may be related to the mechanical removal of the corneal epithelium at the end of the surgery, a procedure we do not normally perform. The transient increase in corneal thickness measured on day 7 of the study in the $100 \mu \mathrm{g} / \mathrm{ml} \mathrm{hEGF}$ group might reflect hyperplasia and hypertrophy of the epithelium in EGF treated eyes, as reported previously by other investigators. $^{2320}$ However, this does not fit with the longer mean time to closure of the defect, since a shorter healing time would be expected with hyperplasia and hypertrophy. It may be that dysregulation of reepithelialisation is induced by a relative overload of hEGF in a concentration of $100 \mu \mathrm{g} / \mathrm{ml}$. Otherwise, hEGF eyedrops were well tolerated and no signs of toxicity could be observed.
It is known that both steroids and antibiotics can retard corneal wound healing, ${ }^{70-22}$ but all patients received the same concomitant topical medication in the operated eye and there should have been no difference between the groups in this respect.

Although increase in corneal wound strength by hEGF has been demonstrated in vivo in animals, it has not been determined in this study because the operated eye has to be sacrificed to estimate stromal wound strength. ${ }^{11} 13$

Patients with essentially normal corneal surface, presumably with normal EGF in the tear film, do not benefit from supplementation of hEGF in the postoperative phase for epithelial healing rate. This study has not addressed the possible advantage of hEGF supplementation to patients undergoing corneal grafting with abnormal ocular surface, sensibility defects, or tear insufficiencies.

During the course of our study Sheardown et $a l^{23}$ reported the optimal concentration of hEGF to accelerate wound healing to be 50 $\mu \mathrm{g} / \mathrm{ml}$ and also found that an increase in exposure time reduced healing time. Taking these findings into account the doses we used may have been too low or too high and the exposure time too short. A gel at a concentration of 50 $\mu \mathrm{g} / \mathrm{ml}$ with controlled release of hEGF might be a more successful adjuvant than eyedrops in slowly healing corneas after penetrating keratoplasty.

Presented in part at the annual meeting of the Association for Research in Vision and Ophthalmology, Sarasota, Florida, USA, May 1994.

Supported by Chiron Vision, Claremont, California, USA.

1 Tripathi RC, Sharath CR, Tripathi BJ. Prospects for epidermal growth factor in the management of corneal disorders. Surv Ophthalmol 1990;34:457-62.

2 Frati L, Daniele S, Delogu A, Covelli I. Selective binding of the epidermal growth factor and its specific effects on the epithelial cells of the cornea. Exp Eye Res 1972;14:135-41.

3 Savage CR, Cohen S. Proliferation of corneal epithelium Savage CR, Cohen S. Proliferation of corneal epithelium
induced by epidermal growth factor. Exp Eye Res 1973;15: induced

4 Ho PC, Davis WH, Elliott JH, Cohen S. Kinetics of corneal epithelial regeneration and epidermal growth factor. Invest Ophthalmol Vis Sci 1974;13:804-9.

5 Watanabe K, Nakagawa S, Nishida T. Stimulatory effects of fibronectin and EGF on migration of corneal epithelial cells. Invest Ophthalmol Vis Sci 1987;28:205-11.

6 Singh G, Foster CS. Epidermal growth factor in alkaliburned corneal epithelial wound healing. Am f Ophthalmol 1987;103:802-7.

7 Woost PG, Brightwell J, Eiferman RA, Schultz GS. Effects of growth factors with dexamethasone on healing of rabbit corneal stromal incisions. Exp Eye Res 1985;40:47-60.

8 Daniele S, Frati L, Fiore C, Santoni G. The effect of the epidermal growth factor (EGF) on the corneal epithelium in humans. Graefes Arch Clin Exp Ophthalmol 1979;210: $159-65$. 
9 Kandarakis AS, Page C, Kaufman HE. The effect of epidermal growth factor on epithelial healing after penetrating keratop $11-5$.

10 Urdea MS, Merryweather JP, Mullenbach GT, Coit D, Heberlein U, Valenzuela P, et al. Chemical synthesis of a gene for human epidermal growth factor urogastrone and its expression in yeast. Proc Natl Acad Sci USA 1983;80: 7461 .

11 Leibowitz HM, Morello S, Stern M, Kupferman A. Effect of topically administered epidermal growth factor on corneal wound strength. Arch Ophthalmol 1990;108:734-7.

12 Brightwell JR, Riddle SL, Eiferman RA, Valenzuela P, Barr PJ, Merryweather JP, et al. Biosynthetic human EGF accelerates healing of neodecadron-treated primate corneas. Invest Ophthalmol Vis Sci 1985;26:105-10.

13 Calel B, Fagerholm P. Human epidermal growth factorthe influence of the healing of surgical closed corneal the influence of the healing of surgical

14 Pels E, Schuchard Y. Organ-culture and endothelial evaluation as a preservation method for human cornea. In tion as a preservation method for human cornea. In:
Brightbill FS, ed. Corneal surgery. St Louis: Mosby, 1986:93-102.

15 Jenkins CDG, McDonnell PJ, Spalton DJ. Randomised single blind trial to compare the toxicity of subconjunctival gentamicin and cefuroxime in cataract surgery. $\mathrm{Br} f$ Ophthalmol 1990;74:734-8.
16 Setten van GB, Viinikka L, Tervo T, Pesonen K, Tarkkanen A, Perheentupa J. Epidermal growth factor is a constant component of normal human tear fluid. Graefes Arch Clin Exp Ophthalmol 1989;227:184-7.

17 Ohashi Y, Motokura M, Kinoshita Y, Mano T, Watanabe H, Kinoshita S, et al. Presence of epidermal growth factor in human tears. Invest Ophthalmol Vis Sci 1989;30:1879-82.

18 Setten van GB, Tervo T, Viinikka L, Pesonen K, Perheentupa J, Tarkkanen A. Ocular disease leads to decreased concentrations of epidermal growth factor in the tear fluid. Curr Eye Res 1991;10:523-7.

19 Elliott JH. Epidermal growth factor: in vivo ocular studies. Trans Am Ophthalmol Soc 1980;78:836-46

20 Ho PC, Elliott JH. Kinetics of corneal epithelial regeneration. Invest Ophthalmol Vis Sci 1975;14:630-3.

21 Srinivasan BD, Kulkarni PS. The effect of steroidal and nonsteroidal anti-inflammatory agents on corneal reepithelialization. Invest Ophthalmol Vis Sci 1981;20:688-91.

22 Stern GA, Schemmer GB, Farber RD, Farber RD, Gorovoy MS. Effect of topical antibiotic solutions on corneal epithelial wound healing. Arch Ophthalmol 1983;101:644-7.

23 Sheardown H, Wedge C, Chou L, Apel R, Rootman DS, Cheng YL. Continuous epidermal growth factor delivery in corneal epithelial wound healing. Invest Ophthalmol Vis Sci 1993;34:3593-600. 